6 - ARTIGO ORIGINAL

\title{
Biocompatibilidade do cimento de fosfato de cálcio implantado no rádio de coelhos
}

Biocompatibility of calcium phosphate cement implanted in radius of rabbits

Paola Castro Moraes ${ }^{2}$, João Guilherme Padilha Filho ${ }^{3}$, Júlio Carlos Canola ${ }^{3}$, Luis Alberto dos Santos ${ }^{4}$, Delphin da Graça Macoris ${ }^{3}$, Antônio Carlos Alessí, Márcio Botelho de Castro ${ }^{6}$, Francisco de Assis Dória Neto ${ }^{2}$

1. Dissertação de Mestrado defendida no programa de Pós-graduação em Cirurgia Veterinária da Faculdade de Ciências Agrárias e Veterinárias, Universidade Estadual Paulista (FCAV-UNESP), Campus de Jaboticabal.

2. Mestre em Cirurgia Veterinária pela FCAV-UNESP.

3. Professor assistente-Doutor do Departamento de Clínica e Cirurgia Veterinária, FCAV-UNESP.

4. Professor Doutor da Faculdade de Engenharia de Materiais da Universidade Federal do Rio Grande do Sul (FRGS).

5. Professor Titular do Departamento de Patologia Veterinária FCAV-UNESP. Doutor em patologia veterinária pela FCAV-UNESP.

\section{RESUMO}

OBJETIVO: Avaliar a biocompatibilidade do cimento de fosfato de cálcio, para verificar sua eficácia como possível substituto ósseo.

MÉTODOS : No presente trabalho, foi utilizado cimento de fosfato de cálcio em rádio de 8 coelhos, separados em dois grupos (GI e GII), referentes aos tempos de observação de 12 e 26 semanas pós-operatórias, a fim de se observar as reações entre este biomaterial e o tecido ósseo do animal. Foram feitas análises radiográficas e de densitometria óptica, além de microscopia óptica e eletrônica de varredura.

RESULTADOS : Observou-se, ao final do experimento, que o cimento à base de fosfato de cálcio foi parcialmente reabsorvido durante o tempo de observação de 26 semanas, apresentando biocompatibilidade, com ausência de reações indesejáveis que pudessem ser atribuídas aos implantes.

CONCLUSÕES : O cimento à base de fosfato de cálcio foi biocompatível e parcialmente reabsorvido no período de 26 semanas de observação. Tempos maiores de observação são necessários para a avaliação da reabsorção.

Descritores: Cimento de fosfato de cálcio. Cimentos ósseos. Biomateriais. Coelhos.

\begin{abstract}
PURPOSE: The objective of this paper was to evaluate the biocompatibility of calcium phosphate cement in radius of rabbits.

METHODS: For this experiment, calcium phosphate were implanted in the radius of 16 rabbits, divided in two groups (GI and GII), according to postoperative follow-up of 12 and 26 weeks, respectively. Reactions of these biomaterials on animal bone tissue were observed. $\mathrm{X}$-ray, optical densitometry, optical microscopy and scanning electron microscopy analyses were performed.
\end{abstract}

RESULTS: It was observed that calcium phosphate cement were partially resorbed during the 26-week follow-up, showing biocompatibility, with absence of inflammatory or other undesirable reactions due to the implants. 
CONCLUSIONS: Calcium phosphate-based cements did not cause inflammatory reactions when in contact with the osseous tissue, and were therefore biocompatible. Follow-up periods longer than 26 weeks are necessary to better evaluate the behavior of calcium phosphatebased cement.

Key words: Calcium phosphates. Bone cements. Biocompatible materials. Rabbits.

\section{Introdução}

Desde épocas passadas, o homem tem-se preocupado em restaurar ou substituir partes danificadas do tecido ósseo humano. Em meados do século XVII, Fallopius implantou uma placa de ouro para restaurar um defeito craniano e, a partir daí, tem-se usado os implantes para a substituição de partes danificadas do sistema ósseo. ${ }^{1}$

Numerosos materiais têm sido utilizados, porém muito poucos apresentam resultados satisfatórios já que a maioria provoca, em maior ou menor grau, resposta imunológica do organismo receptor. Dentre os materiais biológicos encontram-se os enxertos autógenos, que utilizam tecido ósseo do próprio indivíduo, e os enxertos alógenos, que consistem na utilização de tecido ósseo de outro indivíduo, da mesma espécie, para a reconstituição da parte danificada. Destes materiais, os enxertos autógenos são mais utilizados devido à resposta imunológica, sendo sempre compatíveis, favorecendo os processos de revascularização e reparação. $O$ enxerto ósseo pode cooperar com três funções para o processo de consolidação: osteogênese, osteoindução e osteocondução. ${ }^{2,3}$

A procura por um material moldável para promover a reparação óssea tem sido a busca de vários pesquisadores e cirurgiões interessados em acelerar a consolidação de fraturas ou reconstruir defeitos ósseos. ${ }^{4}$

Os biomateriais podem ser definidos como substâncias de origens naturais ou sintéticas que são toleradas de forma transitória ou permanente pelos diversos tecidos que constituem os órgãos dos seres vivos. ${ }^{5}$

O termo "cimento de fosfato de cálcio" (CFC) foi introduzido por Gruninger e colaboradores. ${ }^{6}, 5$ Os CFC são materiais constituídos por um pó e um líquido, os quais, ao serem misturados, formam uma pasta que endurece espontaneamente à temperatura ambiente ou corporal como resultado da precipitação de um ou vários fosfatos de cálcio. ${ }^{7,8}$

As características que determinam os CFC biomateriais atrativos para a reconstituição ou remodelação óssea, são a facilidade de manipulação e moldagem, sem ter de dar forma prévia ao implante, adaptando-se totalmente à forma da cavidade óssea, obtendo um íntimo contato entre o osso e o cimento desde os primeiros estágios da implantação; não aquecem durante o processo de endurecimento, evitando a necrose tecidual no sítio de implantação. ${ }^{9}, 4$ A preparação é feita durante o ato cirúrgico; possuem biocompatibilidade e bioatividade ${ }^{10,11}$

O comportamento biológico "in vivo" dos CFC tem sido exaustivamente estudado em diversos modelos animais. ${ }^{12,5}$ Genericamente, os CFC comportam-se "in vivo" de maneira semelhante às biocerâmicas de fosfato tricálcico, ou seja, são reabsorvidos devido à atividade osteoclástica, formando ao mesmo tempo novo tecido ósseo na interface osso-implante. Desta forma, os CFC não atuam como substitutos permanentes do osso, apenas temporário, sendo lentamente substituídos por tecido ósseo de nova formação. Este comportamento típico tem sido denominado osteotransdutividade. A velocidade em que esse fenômeno ocorre, depende fortemente do tipo de CFC, do sítio de implantação e da idade do paciente receptor, entre outros fatores. ${ }^{2}$

As avaliações radiográficas e microscópicas são métodos importantes para se analisar o comportamento da reconstituição óssea. O uso da radiografia convencional para avaliar 
quantitativamente a reabsorção do cimento à base de cálcio, é limitada, devido ao fato de este material poder ser substituído por tecido ósseo do hospedeiro, radiopaco também. Assim sendo, para melhor avaliar o comportamento desse material, recomenda-se a utilização da densitometria óptica radiográfica ${ }^{13}$. A densidade óptica da imagem radiográfica guarda correlação logarítmica inversa com a radiopacidade do material radiografado que condiciona a quantidade de radiação que atravessa o mesmo e sensibiliza a película radiográfica. Dessa forma, quanto mais radiopaco o material analisado, menor a densidade óptica verificada na imagem radiográfica do mesmo ou, em termos de tecido ósseo, quanto maior a ossificação ou mineralização do material, menor a densidade óptica mensurada em sua imagem radiográfica, sendo essa a base física dos métodos de densitometria óssea. ${ }^{14}$

Assim sendo, com este trabalho, objetivou-se avaliar a biocompatibilidade e o comportamento do cimento à base de fosfato de cálcio em rádio de coelhos, durante os períodos pósoperatórios de 12 e 26 semanas. Análises radiográficas, densitometria óptica, microscopia óptica e eletrônica de varredura foram etapas deste trabalho.

\section{Métodos}

\section{Animais}

O experimento foi realizado de acordo com o Comitê de Ética e Bem-Estar Animal da FCAVUNESP-Jaboticabal. Foram utilizados 8 animais da espécie leporina, raça Nova Zelândia, cor branca, adultos jovens, machos ou fêmeas, provenientes do Setor de Cunicultura da Faculdade de Ciências Agrárias e Veterinárias - UNESP - Campus de Jaboticabal.

\section{Grupos experimentais}

Os animais foram separados em 2 grupos contendo 4 animais cada um, correspondentes aos tempos de avaliação pós-operatória de 12 e 26 semanas.

\section{Cimentos ósseos}

Os implantes de cimento ósseo foram fornecidos pelo Departamento de Engenharia de Materiais da Faculdade de Engenharia Mecânica da UNICAMP- Campinas-SP, e avaliadas de acordo com o ISO/TR 10993-6- Biological Evaluation of Medical Devices- Tests for local effects after implantation. Todas as amostras tinham o formato cilíndrico de $2 \mathrm{~mm}$ de diâmetro e $6 \mathrm{~mm}$ de comprimento, esterilizadas em autoclave.

\section{Pré-operatório e anestesia}

Quarenta minutos antes do início da cirurgia, os animais receberam antibioticoterapia à base de Ampicilina, na dose de $20 \mathrm{mg} / \mathrm{kg}$, por via subcutânea.

Os animais foram submetidos à anestesia dissociativa à base de cloridrato de Quetamina, na dose de $25 \mathrm{mg} / \mathrm{kg}$, associado à Xilazina, na dose de $5 \mathrm{mg} / \mathrm{kg}$, diluídos em uma mesma seringa por via intramuscular, dez minutos após a aplicação de $0,5 \mathrm{mg}$ de Sulfato de atropina por animal, via intramuscular.

\section{Procedimento cirúrgico}

Com os membros torácicos tricotomizados e preparados assepticamente para a cirurgia, foi feita uma incisão de aproximadamente $1 \mathrm{~cm}$ na porção distal da face medial do membro, 
acessando desta maneira o rádio, através de divulsão do tecido celular subcutâneo. Foi feito um orifício com broca de $2 \mathrm{~mm}$ de diâmetro, utilizando uma perfuratriz, atingindo as duas corticais do rádio, da face medial à lateral, onde o implante foi colocado. A pele foi suturada de maneira rotineira.

\section{Pós-operatório}

A Ampicilina foi mantida por 6 dias após a cirurgia. O Ketoprofeno foi fornecido como analgésico na dose de $1 \mathrm{mg} / \mathrm{Kg}$ de peso, por via subcutânea, no pós-operatório imediato e a cada 24 horas, por 2 dias.

Os animais foram mantidos em gaiolas isoladas durante todo o período de observação, recebendo ração balanceada e água ad libitum.

\section{Avaliação radiográfica}

Os animais foram radiografados no período pós-operatório imediato e mensalmente, até o momento do sacrifício, correspondendo aos tempos de 12 e 16 semanas. Foram realizadas projeções mediolateral e craniocaudal.

\section{Sacrifício dos animais}

Os animais foram sacrificados com injeção rápida de tiopental sódico por via intrfavenosa associado ao cloreto de potássio até parada completa dos batimentos cardíacos. Após o sacrifício, os animais foram encaminhados para colheita dos fragmentos para exame de microscopia óptica e eletrônica de varredura.

\section{Densitometria óptica e Índice de Mineralização (IM)}

$\mathrm{Na}$ tentativa de se estabelecer um padrão de avaliação da radiopacidade do implante, com uma base constante e objetiva, optou-se pela mensuração da densidade óptica dos implantes. A partir desta, propôs-se a utilização de um valor de comparação, denominado Índice de Mineralização, inversamente proporcional à densitometria óptica (DO), que considera áreas de maior e menor exposição de cada radiografia avaliada como os extremos positivo e negativo de radiopacidade, permitindo a atribuição de um valor numérico relativo para a radiopacidade de cada implante. Foi utilizado para tal procedimento um densitômetro digital. Para se determinar o valor do índice de mineralização, foi realizado um gráfico, onde em X estavam os valores de mineralização de 10 a 0 . Em Y, os valores médios de DO dos filmes radiográficos, da área mais radiopaca e da área menos radiopaca, no centro da película. Obtiveram-se, portanto, para cada exposição radiográfica, dois pontos, que foram ligados por uma reta. A seguir, o valor médio da DO de cada implante, em cada momento do experimento, foi inserido nesse gráfico e, portanto, obteve-se o valor do índice de mineralização (IM) no cruzamento deste valor com a reta (Figura 1). 


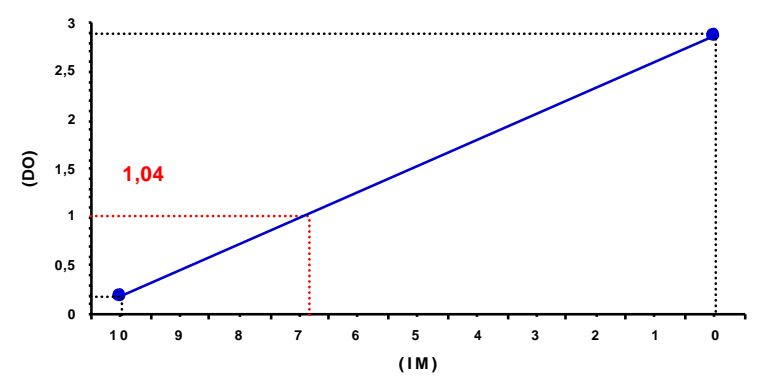

FIGURA 1 - Exemplo do cálculo do Índice de Mineralização (IM).

Área mais radiopaca da radiografia (média): $\mathrm{DO}=0,2$

Área menos radiopaca da radiografia (média): $\mathrm{DO}=2,9$

DO média do implante: $1,04 \quad \mathrm{IM}=6,8$

\section{Análise estatística}

Foi realizada a densitometria óptica em todas as radiografias. Com os valores médios das exposições radiográficas (película e implante), obteve-se o índice de mineralização. A partir desses valores, realizou-se o delineamento inteiramente casualizado, no esquema em parcela subdividida, tendo o tratamento (cimento) como parcela e os tempos pós-operatórios como subparcela. As médias foram comparadas pelo teste de Tukey ( $\mathrm{p}$ ? 0,05).

\section{Avaliação histológica}

Os fragmentos de osso hospedeiro, contendo o implante, foram coletados e fixados em formalina a $10 \%$ por, no mínimo, 4 dias, após os quais foram lavados e descalcificados em ácido tricloroacético a $20 \%$.

Posteriormente à descalcificação, os fragmentos foram desidratados em etanol, diafanizados em xilol, incluídos em parafina e seccionados em cortes de $5 \mathrm{u}$ em micrótomo. As lâminas foram coradas pela técnica da hematoxilina-eosina (H.E.) e o material examinado ao microscópio óptico, a fim de se observar as interações das interfaces osso/implante.

\section{Avaliação por microscopia eletrônica de varredura (MEV)}

Outras amostras também foram colhidas e fixadas em glutaraldeído a $2.5 \%$ em tampão de cacodilato de sódio a $0,1 \mathrm{M}$ e $\mathrm{PH}$ entre 7,4 a 7,8 , durante 8 horas, à temperatura de 4 ? $\mathrm{C}$, e enviados para a microscopia eletrônica de varredura para a avaliação do comportamento do cimento. A preparação do material foi feita através das etapas de fixação em tetróxido de ósmio, desidratação com álcool, secagem no ponto crítico, montagem da amostra e metalização com ouro. Após esta operação, as amostras puderam ser observadas ao MEV.

\section{Resultados}

\section{Avaliação radiográfica}

Aos 30 dias de pós-operatório, iniciou-se o processo de recobrimento do implante por tecido ósseo, sendo que o processo de reabsorção foi detectado somente aos 90 dias, progredindo até os 180 dias . A reabsorção variou de animal para animal, sendo observada em menor ou maior intensidade (Figura 2). 

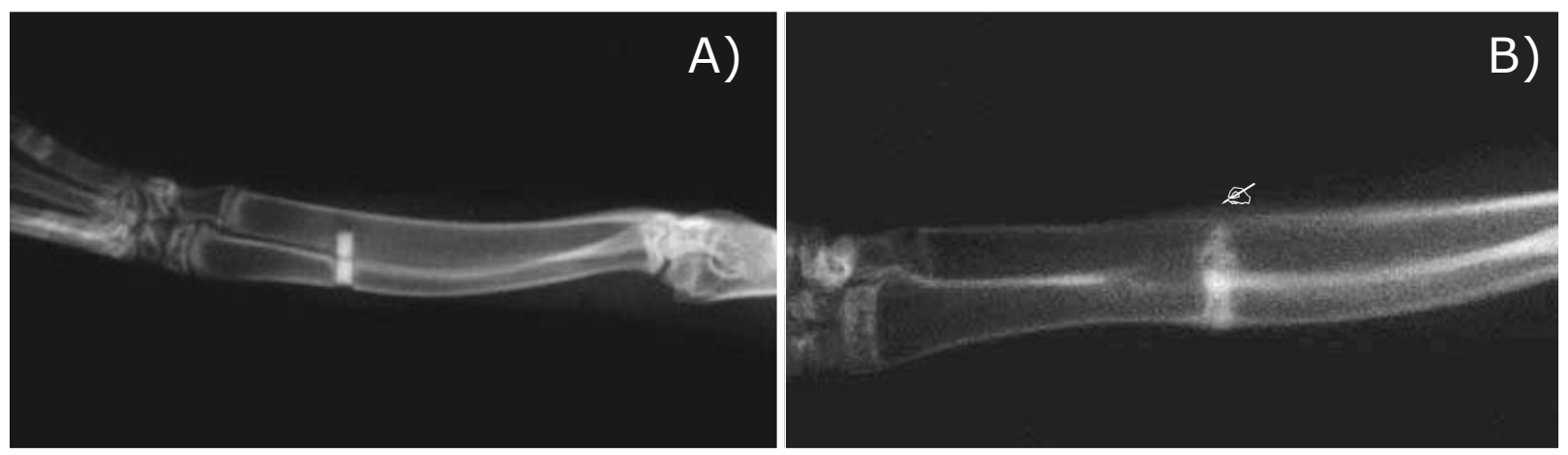

FIGURA 2 - Imagens ilustrando o aspecto radiográfico do cimento de fosfato de cálcio, no período pós-operatório imediato (A) e após 180 dias, com o processo de reabsorção avançado $(\mathrm{B})$.

\section{Densitometria óptica e índice de mineralização (IM) - análise estatística}

A análise estatística mostrou que os implantes à base de fosfato de cálcio apresentaram variação do valor do IM de acordo com o tempo do pós-operatório, havendo aumento significativo aos 90 dias e queda aos 150 dias.

\section{Avaliação histológica}

Todas as amostras analisadas apresentaram, ao redor do implante, formação de cápsula de tecido conjuntivo após 12 semanas de observação. A desmineralização do material, indicativo de início de reabsorção, é mostrado na Figura 3. Não foi detectada nenhuma reação tipo corpo estranho, que pudesse ser atribuída aos implantes.

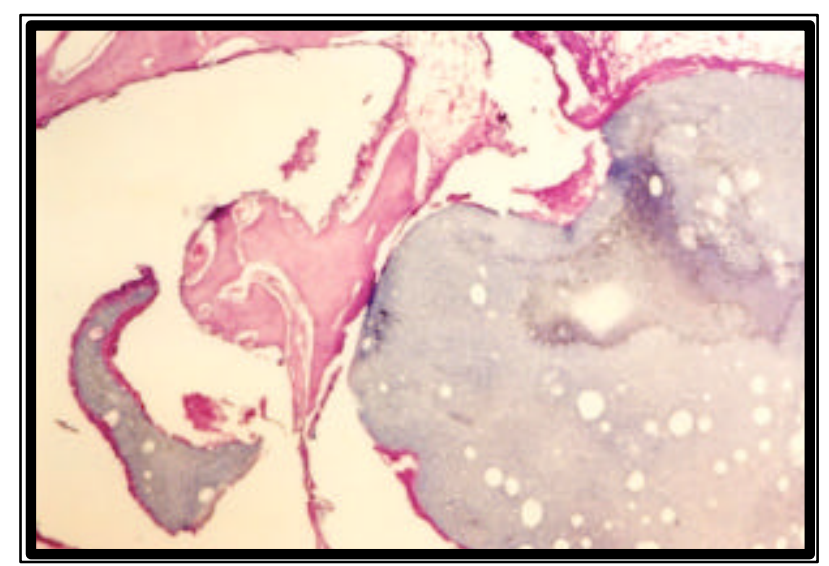

FIGURA 3 - Fotomicrografia óptica do implante de cimento de fosfato de cálcio, implantado no rádio de coelhos com a seta maior mostrando a desmineralização do material. A seta menor mostra o envolvimento do material por tecido conjuntivo aumento de $4 \mathrm{x}$, tempo pós-operatório 12 semanas. 
Houve recobrimento por tecido ósseo nos implantes em todos os animais, sendo que, nos animais com avaliação pós-operatória de 26 semanas, este recobrimento mostrou-se mais evidente (Figura 4) do que nos animais com avaliação de 12 semanas do pós-operatório. Não houve evidências de reabsorção do implante, nem substituição do mesmo por tecido ósseo, na microscopia eletrônica de varredura.

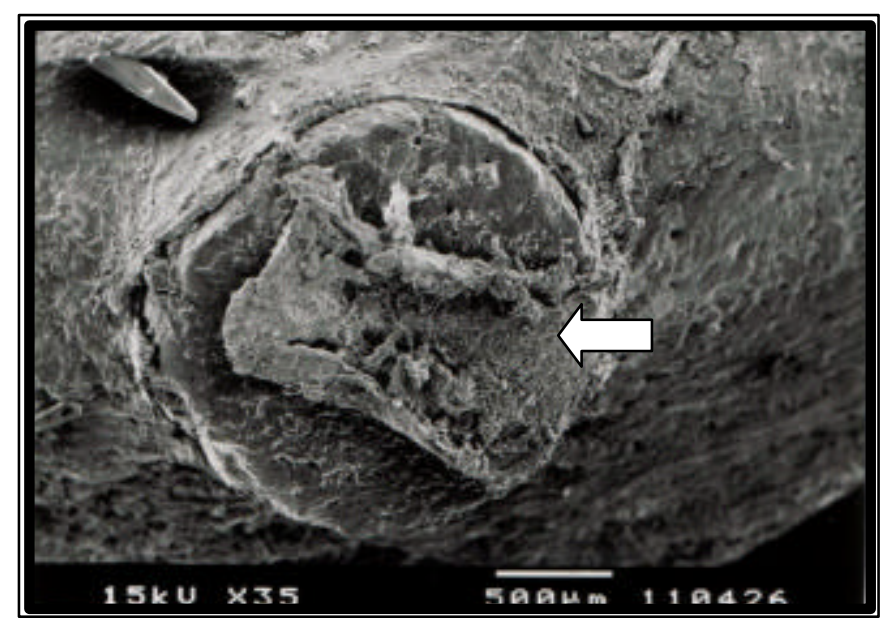

FIGURA 4 - Eletromicrografia de varredura do implante à base de fosfato de cálcio, em rádio de coelhos. Observar o recobrimento parcial por tecido ósseo (seta). (Tempo do pós operatório: 12 semanas; aumento 35X).

\section{Discussão}

Os cimentos à base de fosfato de cálcio são os biomateriais que foram concebidos para solucionar os problemas relacionados às cerâmicas de fosfato de cálcio e outros materiais anteriormente utilizados. ${ }^{8}$ As características que tornam os cimentos a base de fosfato de cálcio materiais ideais são a biocompatibilidade, ausência reação exotérmica, ser moldável ao defeito ósseo, e ser substituído por tecido ósseo do hospedeiro. ${ }^{13}$

$\mathrm{O}$ uso da radiografia convencional para avaliar quantitativamente a reabsorção do cimento à base de cálcio é limitada, devido ao fato do cimento poder ser substituído por tecido ósseo hospedeiro, radiopaco também ${ }^{13}$. Neste trabalho, a avaliação radiográfica não foi completamente eficaz para se observar a reabsorção dos materiais implantados, devido também ao tamanho reduzido do implante.

Para melhor avaliação do comportamento desses materiais, foi utilizada a densitometria óptica radiográfica (DO). Rahal e col $^{15}$ utilizaram a densitometria óptica radiográfica para avaliar a desmineralização óssea ocorrida no hiperparatireoidismo secundário nutricional induzido em gatos e concluíram que o método é simples e eficiente. Neste estudo, pode-se observar as alterações da densidade óptica radiográfica, conseqüentes do processo de reabsorção do biomaterial analisado.

A análise estatística mostrou aumento significativo a 5\% do valor do índice de mineralização aos 90 dias de pós-operatório e diminuição aos 150 dias, o que corresponde ao remodelamento ósseo nos 90 dias e o início do processo de reabsorção do material implantado, aos 150 dias.

Os cimentos à base de fosfato de cálcio têm a propriedade de serem osteocondutivos, ou seja, estimularem a neoformação óssea conseqüente da reabsorção do implante. Vários pesquisadores confirmaram esta propriedade, em diferentes estudos. Schimitz e col. ${ }^{4}$ utilizaram cimento de fosfato de cálcio para reconstrução de defeitos craniofaciais em cães e após 6 meses de avaliação, observaram neoformação óssea periosteal e endosteal, 
proporcionada pelo material utilizado. Kurashina e col. ${ }^{12}$ obtiveram os mesmos resultados, em mandíbula de coelhos. Neste estudo, houve reabsorção parcial do material empregado, porém não houve neoformação óssea no local reabsorvido.

De acordo com Yuan e col. ${ }^{8}$, a substituição do cimento de fosfato de cálcio por tecido ósseo pode ser explicada pela osteocondutividade ocorrida no cimento implantado no tecido ósseo; osteoclastos reabsorvem o material por fagocitose e osteoblastos produzem a neoformação óssea. No presente trabalho, foram identificados osteoclastos ao redor do implante na microscopia óptica, o que sugere a reabsorção do mesmo durante o período de observação. No entanto, não foram encontrados osteoblastos no local, o que explica a ausência de neoformação óssea. Estes pesquisadores relataram formação de tecido conjuntivo ao redor do implante somente após seis meses da implantação, contrariando o que encontramos neste estudo, onde após 12 semanas (3 meses) de implantação, o tecido conjuntivo ao redor do implante foi observado através da avaliação histológica.

Scimitz e col. ${ }^{4}$ registraram que a reabsorção dos cimentos à base de fosfato de cálcio é pouco documentada na literatura. A reabsorção deste cimento é contínua in vivo, quando a superfície do cimento é recoberta por tecido mole, e é inibida pela formação de tecido ósseo na superfície $^{10}$. Estes pesquisadores sugeriram que a reabsorção é lenta, podendo-se encontrar material até 2 anos após a implantação. Desta forma, a presença de tecido conjuntivo em todos os tipos de cimentos, tanto para 12 quanto para 26 semanas de implantação, permite inferir que o processo de reabsorção do cimento ainda pode ocorrer para períodos maiores de implantação, podendo permitir sua substituição por tecido ósseo. Assim, tempos de implantação superiores a 26 semanas se fazem necessários para melhor avaliação dos materiais.

$\mathrm{Na}$ microscopia eletrônica de varredura verificou-se recobrimento dos implantes por tecido ósseo e ausência de reação inflamatória. Resultados semelhantes têm sido descritos em outros experimentos. ${ }^{9,} 16$ No entanto, para uma melhor avaliação deste material na MEV, o aumento utilizado deve ser maior do que o realizado neste trabalho.

\section{Conclusões}

1. O cimento à base de fosfato de cálcio, utilizado neste experimento não provocou reações inflamatórias no local de contato com o tecido ósseo, sendo biocompatível.

2. Todas as amostras foram parcialmente reabsorvidas durante o período de observação pósoperatória, segundo os resultados obtidos.

3. Tempos de observação superiores a 26 semanas são necessários para melhor avaliação do comportamento do cimento de fosfato de cálcio.

\section{Referências}

1. Sanan A, Haines SJ. Repairing holes in the head: a history of cranioplasty. Neurosurgery 1997;40(3):588-603.

2. Parker RB. Injertos ósseos en cirugía de pequeños animales. Waltam Focus 1995;5(2):90-9.

3. Fitch R, Kerwin SC, Newman-Gage H, Sinibaldi KR. Bone autografts and allografts in dogs. Cont Educ Art 1997;19(5):559-75.

4. Schmitz JP, Hollinger JO, Milan SB. Reconstruction of bone using calcium phosphate bone cement: a critical review. J Oral Maxillofac Surg 1999;57:1122-6.

5. Santos LA, Oliveira LC, Rigo EC, Carrodeguas RG, Boschi AO, De Arruda AC. Influence of polymeric assitives on the mechanical properties of a-tricalcium phosphate cement. Bone 1999;25(2):99-102.

6. Mirtchi AA, Lemaitre J, Munting E. Calcium phosphate cements: study of the beta-tricalcium phosphate--dicalcium phosphate--calcite cements. Biomaterials 1990;11(2):83-8.

7. Carrodeguas RG, Mondejar SP, Santos LA, Rigo ECS, Boschi AO. Cimentos de fosfato de cálcio. Biotecnologia 1999;(10):30-2. 
8. Yuan H, Li Y, Brujin JD, Groot K, Zhang X. Tissue responses of calcium phosphate cement: a study in dogs. Biomaterials 2000;21:1283-90.

9. Driessens FCM, Plannel JA, Boltong MG, Khairon J, Ginebra MP. Osteotransductive bone cements. Proc Inst Mech Eng 1998;212(6): 427-35.

10. Knabe C, Driessens FCM, Plannel JA, Gildenhaar R, Berger C, Reif D, Fitzner R, Radlanski RJ, Gross U. Evaluation of calcium phosphates and experimental calcium phosphate bone cements using osteogenic Cultures. J Biomed Mater Res 2000;52:498-508.

11. Pioletti DP, Takei H, Lin T, Landuyt P, Ma QJ, Kwon SY, Sung KL. The effects of calcium phosphate particles on osteoblast functions. Biomaterials 2000;21:1103-14.

12. Kurashina K, Kurita H, Kotani A, Kobayashi S, Kyoshima K, Hirano M. Experimental cranioplasty and skeletal augmentation using a a-tricalcium phosphate/dicalcium phosphate dibasic/tetracalcium phosphate monoxide cement: a preliminary short-term experiment in rabbits. Biomaterials 1998;19:701-6.

13. Larsson S, Mattsson T, Bauer TW. Resorbable bone cement for augmentation of internally hip fractures. Ann Chir Gynaecol 1999;88:205-13.

14. Trall DE. Textbook of veterinary diagnostic radiology. 2ed. Philadelphia: Saunders; 1994.

15. Rahal SC, Mortari AC, Caporali EHG, Vulcano LC, Santos, FAM, Takahira RK, Crocci AJ. Densitometria óptica radiográfica na avaliação do hiperparatireoidismo secundário nutricional induzido em gatos jovens. Ciênc Rural 2002;32(3):421-5

16. Kurashina K, Kurita H, Hirano M, Kotani A, Klein CPAT, Groot K. In vivo study of calcium phosphate cement consisting of alpha tricalcium phosphate/dicalcium phosphate dibasic/tetracalcium phosphate monoxide. Biomaterials 1997;18(2):147-55.

\section{Agradecimentos}

A FAPESP, pelo auxílio à pesquisa (Processo nº 00/13499-3).

Ao Departamento de Engenharia de Materiais da Faculdade de Engenharia Mecânica da UNICAMP-Campinas-SP.

Correspondência

Paola Castro Moraes

Av. Caramuru, 2100/424

14030-000 Ribeirão Preto - SP

Tel: (16)3202-4304

(paolacastro@bol.com.br)

Recebimento: 23/03/2004

Revisão: 19/04/2004

Aprovação: 08/05/2004

Conflito de interesse: nenhum

Fonte de financiamento: FAPESP

\section{Como citar este artigo:}

Moraes PC, Padilha Filho JG, Canola JC, Santos LA, Macoris DG, Alessi AC, Castro MB, Dória Neto FA. Biocompatibilidade do cimento de fosfato de cálcio implantado no rádio de coelhos. Acta Cir Bras [serial online] 2004 Jul-Ag;19(4). Disponível em URL: $\underline{\text { http://www.scielo.br/acb [também em CD-ROM]. }}$ 